\title{
TESTING FOR THE ABSENCE OF EXPECTED REAL PROFITS FROM FORWARD MARKET SPECULATION
}

\author{
Charles M. ENGEL* \\ University of Virginia. Charlontesville. VA 2290l, USA
}

Received March 1982, revised version received March 1984

\begin{abstract}
This paper tests for the absence of expected real profits from forward market speculation. It contrasts with the literature that has considered opportunities for expected nominal profit from speculation - that is, profits denominated in one of the currencies. These studies assume money illusion on the part of market participants, but this paper does not. Empirical results fail to find evidence of unexploited real profit opportunities.
\end{abstract}

\section{Introduction}

In recent years, an extensive literature has tested for opportunities for expected profit from forward market speculation. ${ }^{1}$ These tests have invariably assumed money illusion on the part of market participants, in that they have taken one of the currencies as numeraire to measure expected return. The hypothesis that utility-maximizing agents have rational expectations, there are perfect asset markets and there is no risk premium requires a formulation of asset-market equilibrium in which risk-neutral investors have utility over goods, and, thus, are interested in prospective real profits rather than profits denominated in some currency. Tests of the hypothesis of zero anticipated real profits are performed in this paper, and compared to the more common tests of no expected nominal gains from forward market speculation.

The condition that there be no expected profits denominated in the domestic currency is

$$
F_{\mathrm{t}}=E_{\mathrm{t}} S_{\mathrm{t}+1}
$$

where $S$ is the spot exchange rate, $F$ is the one-period ahead forward rate (both are expressed in units of domestic currency per unit of foreign currency), and $E_{t}$ is the expectation conditional on all information available

\footnotetext{
*I would like to thank Jeffrey Frankel, James Hamilton, Robert Hodrick and Richard Meese for their valuable assistance.

'Kohlhagen (1978), Levich (1979) and Frankel (1980) offer good surveys of this literature.
} 
at time $t$. However, if investors have utility over consumption goods, then, in general, condition (1) will not hold.

The first-order condition for expected utility-maximizing speculation by a representative investor is

$$
F_{t}=\frac{E_{t}\left[U^{\prime}\left(C_{t+1}\right) S_{t+1} / P_{t+1}\right]}{E_{t}\left[U^{\prime}\left(C_{t+1}\right) / P_{t+1}\right]}
$$

where $C$ represents real consumption, $1 / P$ is the purchasing power of the domestic currency for the individual, and $U$ is the investor's utility function. [This result is derived in several papers including Stockman (1978), Frenkel and Razin (1980) and Hansen and Hodrick (1983).] Eq. (1) does not follow from (2) unless $S_{t+1}$ is uncorrelated with $U^{\prime}\left(C_{t+1}\right) / P_{t+1}$. This can be seen explicitly by rewriting (2) as:

$$
F_{t}=E_{t} S_{t+1}+\frac{\operatorname{cov}_{t}\left[S_{t+1}, U^{\prime}\left(C_{t+1}\right) / P_{t+1}\right]}{E_{t}\left[U^{\prime}\left(C_{t+1}\right) / P_{t+1}\right]}
$$

where $\operatorname{cov}_{t}$ represents the covariance conditional on information available at time $t$.

Imposing the assumption that investors be risk-neutral transforms (3) into:

$$
F_{t}=E_{t} S_{t+1}+\frac{\operatorname{cov}_{t}\left[S_{t+1}, 1 / P_{t+1}\right]}{E_{t}\left[1 / P_{t+1}\right]},
$$

because risk neutrality implies $U^{\prime}\left(C_{t}\right)$ is a constant. ${ }^{2}$ Suppose that the covariance term were negative, so the currency tends to depreciate when its purchasing power falls. Then,

$$
F_{t}<E_{t} S_{t+1}
$$

which implies that one could expect to make profits in terms of the domestic currency by buying foreign currency forward and then selling the currency at a profit in the spot market one period later. But, if in those states of the world in which one makes a profit in the domestic currency it also turns out that the domestic currency buys fewer goods, then there really may be no

\footnotetext{
'In this simple case of one consumption good, the investor is risk-neutral if his utility is linear in the single good. Condition (4) holds more generally if the investor's indirect utility function can be expressed as linear in income available for consumption. (Obviously a necessary condition for this is that it be possible to construct a price index for the individual.) The underlying utility function must be an affine transformation of a linear homogeneous utility function. This sort of utility function is implied by the requirement that the investor view all assets as perfect substitutes, or that the Arrow-Pratt coefficient of absolute or relative risk aversion be zero.
} 
bargain on the forward market. There would be no expected real profits from speculation.

It would not be correct to conclude from (4) that $F_{t}=E_{t} S_{t+1}+$ a constant. ${ }^{3}$ The last term in eq. (4) contains a covariance and an expectation that are both conditional on information known at time $t$. Since the information sets available to investors vary with time, this term is time-varying.

If eq. (4) is rewritten in the form in which it has appeared most frequently in the literature [see, for example, Boyer (1977), Krugman (1977), Stockman (1978) and Frankel (1979)], it is easy to derive an empirically testable proposition. This condition says that the forward rate should equal the ratio of the expected purchasing powers of the foreign and domestic currencies:

$$
F_{t}=\frac{E_{t}\left(S_{t+1} / P_{t+1}\right)}{E_{t}\left(1 / P_{t+1}\right)}
$$

If we define

$$
e_{t+1}=F_{t} / P_{t+1}-S_{t+1} / P_{t+1}
$$

then (5) is equivalent to

$$
E_{t} e_{t+1}=0 \text {. }
$$

This can be simply interpreted as the requirement that anticipated profits in real terms derived from forward market speculation vanish. In section 2 , the variable $e_{t+1}$ is constructed and condition (6) is tested. This test is compared to the frequently employed test

$$
E_{\mathrm{t}} u_{\mathrm{i}+1}=0
$$

where

$$
u_{t+1}=\log F_{t}-\log S_{t+1}{ }^{4}
$$

\section{Empirical tests}

The variable $e_{t}$ is constructed using exchange rates and forward rates expressed in dollars per unit of foreign currency and a price index in dollar

\footnotetext{
${ }^{3}$ In a paper similar in intent to this paper, Frenkel and Razin (1980) treat the final term in eq. (4) as a constant in their empirical work. The technique used in this paper is a generalization of theirs, in that it allows for the information sets of investors to vary with time.

${ }^{4}$ Note that expression (5) is independent of the way exchange rates are quoted. (It holds whether rates are expressed as the home currency price of a unit of foreign currency, or vice versa.) Thus, Siegel's (1972) paradox does not arise. The paradox does not arise in expression (7) either, although, of course, (7) is inconsistent with expected utility maximization. [Condition (7) would be correct up to a constant if the exchange rate and prices happen to be log-normally distributed - see Hansen and Hodrick (1983).]
} 
terms. Five different series of $e_{i}$ 's are calculated - one each for the dollar/Canadian dollar, dollar/French franc, dollar/German mark, dollar/Japanese yen, and dollar/English pound exchange rates and forward rates. (The price deflator is the same for each of the $e_{t}$ 's.)

In order to test eq. (6), one would want to verify that $e_{t+1}$ is uncorrelated with everything in the time $t$ information set. Although testing against very large information sets would be desirable, given that there is only a finite amount of data, the tests are more powerful if the information sets considered are limited to those that seem particularly likely to be helpful in forecasting $e_{t+1}$. Following the lead of Hansen and Hodrick (1980), here, in one set of tests, $e_{t+1}$ for each currency is regressed on four of its own lagged values; and, in another set, $e_{t+1}$ is regressed on one of its own lags, and one lag for each of the other currencies.

The variable $u_{t}$ is also constructed for the five exchange rates and forward rates. A group of regressions parallel to those run to test (6) are used to test eq. (7).

Eq. (5) must hold if the market is to be in equilibrium in the presence of a risk-neutral investor. If the forward rate deviated from this value, the riskneutral investor would buy or sell foreign currency forward and make a gain in expected utility. We would expect that if the investor entered the market with a large enough volume of trades that he would quickly drive the forward rate back to its equilibrium rate. To test condition (5) directly we would need to know the price deflator of the risk-neutral investor or investors. Since we cannot know this, we must choose some likely price index. Then, it must be realized we are necessarily testing the joint null hypothesis that markets are perfect; investors are risk neutral; they have rational expectations; and, they use the posited price deflator. The standard tests for absence of speculative forward market profit opportunities are also subject to this dictum. Previous tests which have rejected the null hypothesis may have been rejecting the choice of numeraire in which speculative profits are denominated. Thesc tests suffer from the problem that the numeraire that is chosen (one of the currencies) is not one that would be chosen by any agent who has utility over goods. This paper, on the other hand, does not assume investors have money illusion.

Tests are performed for two separate price indices. In one set of tests, the U.S. consumer price index is used as the deflator. Here the hypothesis is that risk-neutral investors are 'average residents' of the United States, and so consume the market basket represented in the calculation of the CPI. The second price index is meant to represent the deflator for a bundle of goods consumed by an 'average resident' in the world. It is a weighted geometric average of consumer prices for six countries (Canada, France, Germany, Japan, the United Kingdom and the United States). [This, for example, is the type of price index constructed by Kouri and Macedo (1978) in their study 
of optimal portfolio holdings.] The weights chosen for the index are the countries' relative shares of GNP. The first five price indices are converted into dollar terms by multiplying them by the dollar per unit of foreign currency exchange rate before they are multiplied into the index.

The data are sampled monthly. The forward rates are one-month ahead bid rates. The corresponding future spot rates are sampled one month later. Actually, some correction is made on the sampling date because of institutional features of foreign exchange markets [see Meese and Singleton (1982)]. The future spot rate that corresponds to the forward value date is contracted two business days prior to the forward value date.

Ideally, we would like the future price level to correspond to the level of prices on the day the spot contract is negotiated. Unfortunately, many of the price indices are not sampled on just one day, and those countries that do report samples for a specific day do not all sample on the same day. The overriding principle for choosing a day to observe the forward rate is that 'current' prices be known when the forward contract is negotiated. That is, we want $e_{t}$ to be known to investors when $F_{t}$ is negotiated. If $e_{t}$ is not in the information set of forward market speculators at time $t$, then it would not be surprising if we found $e_{t}$ were correlated with $e_{t+1}$. Because the U.S. consumer price index is sampled throughout the month, the forward rate is sampled on the first day of the following month. The corresponding future spot rate is sampled on the next to last day of the month. It is clearly a serious problem that the price data do not exactly match up with the exchange rate data. This could introduce a spurious moving average into the observed $e_{t}$ series, or even eliminate some correlation that truly does exist. The data are described more completely in the data appendix.

A frequently encountered problem in testing equations such as (6) and (7), as pointed out by Cumby and Obstfeld (1982), is that the error terms on each of the equations may not have constant variance conditional on the equation's regressors. If this is the case, and the conditional heteroskedasticity is ignored, then incorrect infererence may be drawn from the test statistics. Thus, after each equation was estimated, the residuals were subjected to White's (1980, p. 825) test for homoskedasticity. ${ }^{5}$ If homoskedasticity was rejected, then the tests for absence of expected speculative profits were conducted with White's (p. 820) test statistic, which is consistent even in the presence of heteroskedasticity.

The first set of tests regressed the 'forecast error' $\left(e_{t}\right.$ or $\left.u_{t}\right)$ on four of its own lags, for each of the five exchange rates, from October 1973 to April 1982. Tablc 1 reports the results of the tests for homoskedasticity of the error terms in each of the regressions. The chi-square statistics under the column

\footnotetext{
${ }^{5}$ The White test regresses the square of the regression error on a constant, the right-hand-side variables, and the squares and cross-products of the right-hand-side variables.
} 
Table 1

Homoskedasticity tests

\begin{tabular}{lccc}
\hline Currency & Log & USCPI & WCPI \\
\hline Canadian dollar & 4.309 & 8.606 & 8.937 \\
French franc & 11.924 & 16.112 & 18.732 \\
German mark & 10.840 & 8.152 & 9.577 \\
Japanese yen & $28.565^{\mathrm{s}}$ & $\mathbf{4 7 . 9 9 2 ^ { \mathrm { a } }}$ & $40.982^{\mathrm{a}}$ \\
British pound & 11.922 & 11.613 & 14.692 \\
\hline
\end{tabular}

"Significant at 95 percent level [critical 95 percent chisquare $(14$ d.f. $)=23.7]$.

Note: This table reports chi-square statistics for White's homoskedasticity test. The tests are for constancy of variance of errors in tests for speculative forward market profit opportunities. 'Forecast errors', as in eqs. (6) and (7), are constructed for the exchange rates and forward rates of the dollar in terms of the five currencies. The tests for profit opportunities are regressions of the forecast errors' on a constant and four own lags. The statistics in the 'Log' column test for homoskedasticity of regression errors when 'forecast errors' are formed using the log specification of eq. (7). The other two columns report similar tests when real 'forecast errors', as in eq. (6), are constructed. The column labelled 'USCPI' uses the U.S. consumer price index as the deflator, while the column labelled 'WCPI' uses a world price index.

labelled 'Log' test for the constancy of the error variance in the regression of $u_{t}$ on a constant and four of its own lags. The statistics reported under 'USCPI' and 'WCPI' are tests of homoskedasticity of the error terms in regressions of $e_{t}$ on a constant and four own lags, where $e_{t}$ is constructed using the U.S. consumer price index and the world price index, respectively. In all cases, the test statistics are distributed as chi-square with 14 degrees of freedom. They have a critical value at the 95 percent levels of 23.7. The table shows that homoskedasticity cannot be rejected except in the case of the 'forecast errors' constructed with the dollar/Japanese yen exchange rate. Thus, in testing for the absence of speculative profit opportunities in the case of the dollar/yen rates, White's heteroskedasticity-consistent test statistic must be used. In the other cases, standard likelihood-ratio tests suffice.

Table 2 reports the results of the tests for the absence of the expected gain from forward market speculation, when each forecast error is regressed on a constant and four lags of itself. The chi-square statistics reported are for the joint hypothesis that the constant term and all coefficients are zero. The statistics reported under the column 'Log' are for the test done under the standard log specification [i.e. tests of eq. (7)]. Those reported under 'USCPI' and 'WCPI' test for the absence of expected real profit opportunities using 
Table 2

Tests for the absence of expected speculative profits.

\begin{tabular}{llll}
\hline Currency & Log & USCPI & WCPI \\
\hline Canadian dollar & 3.567 & 2.493 & 2.611 \\
French franc & 1.468 & 2.742 & 2.717 \\
German mark & 6.984 & 7.100 & 7.201 \\
Japanese yen & 2.819 & 1.992 & 2.043 \\
British pound & 2.717 & 3.611 & 3.593 \\
\hline
\end{tabular}

[Critical 95 percent chi-square $(5$ d.f. $)=11.1$.

Note: The table reports chi-square statistics for the test that the constant term and the coefficients are all zero in a regression of 'forecast errors', as in eqs. (6) and (7), on a constant and four own lags. The statistics in the 'Log' column are for tests when the 'forecast errors' are formed using the $\log$ specification of eq. (7). The other two columns report similar tests when real 'forecast errors', as in eq. (6), are constructed. The column labelled 'USCPI' uses the U.S. consumer price index as the deflator, while the column labelled 'WCPI' uses a world price index.

the two price indices. In no case can the null hypothesis of no expected profits be rejected.

The second set of tests regressed the 'forecast error' on one of its own lags and one lag for each of the other currencies, for the period July 1973 to April 1982. Table 3 reports the results of the homoskedasticity tests performed for this group of regressions. Here, for the standard log specification, we cannot reject the hypothesis that the errors are homoskedastic. But for the tests of absence of expected real profits, heteroskedasticity is a problem for four out of the five currencies, with each price deflator.

Table 4 presents chi-square statistics for the hypothesis that the constant term and all coefficients are zero in the second set of regressions. Again, we cannot reject the null hypothesis for any currency. This is true both under the log specification and in those regressions that test for absence of expected real gains from forward market transactions.

The finding of no evidence for rejecting the null hypothesis contradicts the findings of some recent studies [see, for example, Hansen and Hodrick (1980)]. It would be incorrect to attribute this difference to the use of a measure of ex-post real profits from speculation, since the rejection of the null held in the same time period for the usual specification of the test in nominal terms.

On the other hand, it would be incorrect to conclude on the basis of these tests that the misspecification implicit in testing (7) instead of (6) 'does not matter'. Economic theory suggests agents have utility over goods, and that eq. (6) is the correct specification of our null hypothesis. A statistical test of 
Table 3

Homoskedasticity tests.

\begin{tabular}{llll}
\hline Currency & Log & USCPI & WCPI \\
\hline Canadian dollar & 19.881 & 21.668 & 22.766 \\
French franc & 24.780 & $37.736^{\mathrm{a}}$ & $39.500^{\mathrm{a}}$ \\
German mark & 26.470 & $34.833^{\mathrm{a}}$ & $36.128^{\mathrm{a}}$ \\
Japanese yen & 23.092 & $36.252^{\mathrm{a}}$ & $34.832^{\mathrm{a}}$ \\
British pound & 23.400 & $50.722^{\mathrm{a}}$ & $53.854^{\mathrm{a}}$ \\
\hline
\end{tabular}

aSignificant at 95 percent level [critical 95 percent chisquare $(20$ d.f. $)=31.4]$.

Note: This table reports chi-square statistics for Whites homoskedasticity test. The tests are for constancy of variance of errors in tests for speculative forward market profit opportunities. 'Forecast errors', as in eqs. (6) and (7), are constructed for the exchange rates and forward rates of the dollar in terms of the five currencies. The tests for profit opportunities are regressions of the forecast errors' on a constant, one own lag, and one lag of the 'forecast errors' for each other currency. The statistics in the 'Log' column test for homoskedasticity of regression errors when 'forecast errors' are formed using the log specification of eq. (7). The other two columns report similar tests when real 'forecast errors', as in eq. (6), are constructed. The column labelled 'USCPI' uses the U.S. consumer price index as the deflator, while the column labelled 'WCPI' uses a world price index.

Table 4

Tests for the absence of expected speculative profits.

\begin{tabular}{llll}
\hline Currency & Log & USCPI & WCPI \\
\hline Canadian dollar & 3.371 & 5.032 & 5.648 \\
French franc & 5.796 & 6.067 & 5.826 \\
German mark & 8.810 & 5.785 & 6.238 \\
Japanese yen & 5.863 & 4.901 & 5.246 \\
British pound & 8.186 & 5.925 & 6.692 \\
\hline
\end{tabular}

[Critical 95 percent chi-square $(6$ d.f. $)=12.6$.]

Note: This table reports chi-square statistics for the test that the constant term and the coeflicients are all zero in a regression of 'forecast errors', as in eqs. (6) and (7), on a constant, one own lag, and one lag of the 'forecast errors' for each other currency. The statistics in the 'Log' column are for tests when the 'forecast errors' are formed using the $\log$ specification of eq. (7). The other two columns report similar tests when real 'forecast errors', as in eq. (6), are constructed. The column labelled 'USCPl' uses the U.S. consumer price index as the deflator, while the column labelled 'WCPI' uses a world price index. 
whether coefficients in a regression of $u_{t+1}$ [as defined in (7)] on information available at time $t$ are zero cannot shed much light on the null hypothesis eq. (6). There is some possibility that with more information about the joint distributions of exchange rates and prices the econometrician might be able to draw some inferences about the null hypothesis from such a test. Despite the data limitations, the direct test proposed here might be a more plausible approach to testing eq. (6). Substitution of an imperfect price deflator for the use of no price deflator could be a wise choice in tests of the absence of anticipated real gains from forward exchange market speculation.

It is generally accepted that tests of market efficiency that look for speculative profits on forward market transactions are necessarily tests of the joint null hypothesis of perfect asset markets, rational expectations, and a zero risk premium. There has been little recognition of the implicit need to choose a standard by which to measure profits. All tests of the type discussed in this paper are joint tests of the above hypotheses and the price index (if any) chosen to deflate the nominal forecast error. The tests usually performed are in general inconsistent with the hypothesis that agents have utility over goods. It is possible to test a correctly specified null hypothesis, and that is done here. The null cannot be rejected on the basis of the tests performed in this study.

\section{Data appendix}

The 'world price index' used in constructing $e_{t}$ is a weighted geometric average of consumer prices for the six countries with weights equal to their relative GNPs in 1977. The actual weights are 0.047 for Canada; 0.097, France; 0.138, Germany; 0.189, Japan; 0.066 United Kingdom; and 0.463, United States. The first five price indices are converted into dollar terms by multiplying them by the exchange rate (described below) before they are entered into the price index. All of the price indices are from the International Financial Statistics tape, line 64.

The prices in the various indices are sampled on various days in the month. U.S. prices are sampled in three 6-day pricing cycles starting at the beginning of each month and usually ending no later than the 26th. However, in months with holidays sampling may occur on later dates. (Source: telephone conversations with Patrick Jackman, Bureau of Labor Statistics.) No other price index samples prices at any later date.

The forward rates are bid rates at 10 a.m., as are the spot rates (source: D.R.I.). The forward rates are sampled on the first day of the month and the spot rate on the next to last day of the month. Thus, for a typical $e_{t}$, the forward rate is sampled on the first of the month, the future spot rate is sampled towards the end of that same month, and the price index is for prices collected in that month. Corrections on sampling dates were made for holidays. All data is available from the author on request. 


\section{References}

Boyer, R., 1977, The relation between the forward rate and the expected future spot rate, Intermountain Economic Review 8, 14-21.

Cumby, R. and M. Obstfeld, 1982, International interest-rate and price-level linkages under flexible exchange rates: A review of recent evidence, NBER Working Paper Series, no. 921.

Frankel. J., 1979, The diversifiability of exchange risk, Journal of International Economics 9, 379-393.

Frankel, J., 1980, Tests of rational expectations in the forward exchange market, Southern Economic Journal 46, 1083-1101.

Frenkel, J. and A. Razin, 1980, Stochastic prices and tests of efficiency of foreign exchange markets, Economic Letters 6, 165-170.

Hansen, L.P. and R. Hodrick, 1980, Forward exchange rates as optimal predictors of future spot rates: An econometric analysis, Journal of Political Economy 88, 829-853.

Hansen, L.P. and R. Hodrick, 1983, Risk averse speculation in the forward foreign exchange market: An econometric analysis, in: J. Frenkel, ed., Exchange rates and international macroeconomics (University of Chicago Press, Chicago).

Kohlhagen, S., 1978, The behavior of foreign exchange markets - A critical survey of the empirical literature, Monograph 1978-3, New York University.

Kouri, P. and J. de Macedo, 1978, Exchange rates and the international adjustment process, Brookings Papers on Economic Activity 1, 111-150.

Krugman, P., 1977, Essays in flexible exchange rates, Ph.D. dissertation, M.I.T.

Levich, R., 1979, On the efficiency of markets for foreign exchange, in: R. Dornbusch and J. Frenkel, eds., International economic policy: Theory and evidence (Johns Hopkins, Baltimore) 246-267.

Meese, R. and K. Singleton, 1982, On unit roots and the empirical modeling of exchange rates, Journal of Finance 37, 1029-1037.

Siegel, J., 1972, Risk, interest rates and the forward exchange, Quarterly Journal of Economics 86, 303-309.

Stockman, A., 1978, Risk, information and forward exchange rates, in: J. Frenkel and H.G. Johnson, eds., The economics of exchange rates (Addison-Wesley, Reading, Mass.) 159-178.

White, H., 1980, A heteroskedasticity-consistent covariance matrix estimator and a direct test for heteroskedasticity, Econometrica 48, 817-838. 